\title{
Preliminary Hybrid Modeling of the Panama Canal: Operations and Salinity Diffusion
}

\author{
Luis Rabelo, ${ }^{1}$ Mario Marin, ${ }^{1}$ Petros Xanthopoulos, ${ }^{1}$ Carlos Arellano Lennox, ${ }^{2}$ \\ Pedro Coiduras, ${ }^{2}$ Bernardo Campos, ${ }^{2}$ Luz Andrade, ${ }^{3}$ Ricardo Collins, ${ }^{3}$ Erwin Atencio, ${ }^{3}$ and \\ Daryelis Pitty \\ ${ }^{1}$ Industrial Engineering and Management Systems Department, College of Engineering, University of Central Florida, \\ Orlando, FL 32816, USA \\ ${ }^{2}$ Naval Engineering Department, College of Engineering, Columbus University, Panama, Panama \\ ${ }^{3}$ Information Systems Department, College of Engineering, Universidad Latina de Panama, Ricardo J. Alfaro Avenue, Panama, Panama
}

Correspondence should be addressed to Luis Rabelo, lrabelo@mail.ucf.edu

Received 14 October 2011; Revised 24 January 2012; Accepted 25 January 2012

Academic Editor: Farouk Yalaoui

Copyright (c) 2012 Luis Rabelo et al. This is an open access article distributed under the Creative Commons Attribution License, which permits unrestricted use, distribution, and reproduction in any medium, provided the original work is properly cited.

\begin{abstract}
This paper deals with the initial modeling of water salinity and its diffusion into the lakes during lock operation on the Panama Canal. A hybrid operational model was implemented using the AnyLogic software simulation environment. This was accomplished by generating an operational discrete-event simulation model and a continuous simulation model based on differential equations, which modeled the salinity diffusion in the lakes. This paper presents that unique application and includes the effective integration of lock operations and its impact on the environment.
\end{abstract}

\section{Introduction}

The Panama Canal currently carries 4 percent of the world's trade goods, and it is an important competitor in some very important shipping routes. For example, the canal currently handles about $16 \%$ of the United States maritime trade, and more than $25 \%$ of the containerized trade between north east Asia and the east coast of the United States [1,2]. Within the Republic of Panama, the Canal is responsible for the growth of the terminal cities of Panama and Colon (these cities and their metropolitan areas have $70 \%$ of the population of the Republic of Panama).

The navigational channel of the Panama Canal is about 50 miles $(80 \mathrm{~km})$ long and extends from the Caribbean Sea to the Pacific ocean (see Figure 1). The canal includes Gatun Lake, a fresh water lake which has a surface area of $436 \mathrm{Km}^{2}$ $\left(168.4 \mathrm{mi}^{2}\right)$ at $26 \mathrm{~m}(85 \mathrm{ft})$ above mean sea level. A series of locks on the waterway is used to raise and lower ships transiting to and from Gatun Lake to the oceans by moving water into and out of the lake using the force of gravity $[3,4]$.
In addition, Gatun Lake is utilized to provide fresh water to the terminal cities of Panama and Colon.

Currently the canal is operating at almost $95 \%$ of its maximum sustainable capacity which limits its ability to capture the increasing demand that will occur within the next 50 years [5]. Additionally, port operators at both sides of the Canal are betting on larger and more efficient postPanamax ships (e.g., "ships that do not fit in the canal, such as supertankers and the largest modern container ships") [6]. Therefore, Panama has started the expansion of the Panama canal. This project will double the capacity of the Panama Canal by 2014 by allowing more and larger ships to transit.

The Panama Canal expansion through a third set of locks presents new challenges. One challenge is the potential increase in the salinity of Gatun Lake above permissible levels. Using this scenario we designed and propose to implement a system that allows us to estimate increases and/or decreases in salinity in Gatun Lake so that we can alternatively design and implement plans to reduce or mitigate adverse effects. 


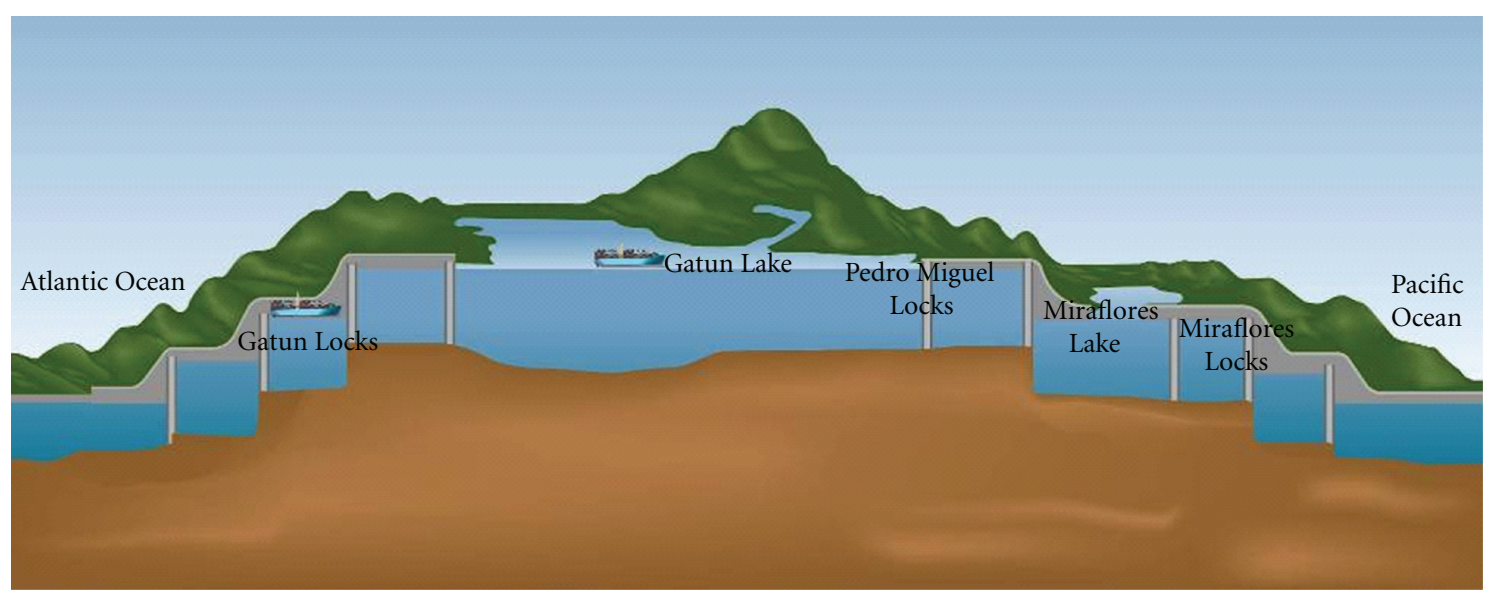

Figure 1: Schematic of the Panama Canal.

To understand this operational system and its complexities, we have to both describe and model its structure. Therefore, we have created a basic hybrid simulation model of the current Panama Canal operations that also shows the diffusion of the saline ocean water into Gatun Lake. The behavior of the Panama Canal, taking into consideration the transit of ships and the diffusion of salinity, is determined by the interaction of discrete event and continuous dynamics. We decided to combine explicitly a discrete event model (which models the operations and the transit of ships) and a continuous model which includes the respective differential equations to model the exchange of water and salt based on the mass balance and salt balance dynamics. AnyLogic provides the mechanisms to model this type of hybrid systems [7]. AnyLogic allows us, using hybrids statecharts (a form of Hybrid Automata), to combine, explicitly, the basic model of differential equations with the basic model of discrete event systems, which are finite state automata. The objective is to have a simulation model which can model the current transit rates of the Panama Canal (based on appropriate 95\% confidence intervals) and the salinity levels with a mean absolute error lower than $0.02 \mathrm{ppt}$ as recommended by Subject Matter Experts (SMEs).

This paper discusses the preliminary phase of this project where the current conditions of the Panama Canal are modeled using a basic hybrid model in AnyLogic. A potential increase in salinity due to the expansion of the Panama Canal with a new set of locks will be considered in a future paper.

\section{Salinity of the Lakes}

Salinity refers to the mass quantity of dissolved salts per unit of water mass or water volume ( 1 unit $=1$ liter $)$. Seawater's salinity $(S)$ amounts to 35 parts per thousand (ppt). The chloridity $(\mathrm{Cl})$, which is sometimes used, represents the mass quantity of chloride ions per unit of water mass or water volume. The $\mathrm{Cl}$ of fresh water should not exceed 0.2 to $0.25 \mathrm{ppt}$. This fresh water limit corresponds to a salinity value of 0.4 to 0.5 ppt. The relationship between $S$ and $\mathrm{Cl}$ is: $S=$ $0.03+1.905^{*} \mathrm{Cl}$ (valid for $S$ and $\mathrm{Cl}>1 \mathrm{ppt}$ ) [8].
The salinity diffusion was modeled using the exchange of mass transfer [9]. This involved the study of different volumes and salinity gradients of the Panama Canal System: Water systems and Locks. In addition, it was complemented by a data collection using historical data provided by the Panama Canal Authority (and data collected by the team). For convenience reference, the six locks (see Figure 1) are identified by the following notation [10]:

\section{L1: lowest lock on the Pacific side;}

L2: lock between Miraflores Lake and L1;

L3: lock between Miraflores Lake and Gatun Lake (Pedro Miguel);

\section{L4: highest lock directly connected to Gatun Lake;}

L5: middle lock on Atlantic side;

L6: lowest lock connected to Atlantic ocean.

The Panama Canal has two lakes: Gatun and Miraflores. Water from these two lakes is used for the Panama Canal System to fill the navigation locks. Salt water from the Pacific and Atlantic Oceans gets added to the lakes during the transit of the ships. In addition, water from the lakes is lost to the sea during the same process. The Gatun Lake supplies fresh water to the population of Panama and Colon Cities for drinking purposes. The Miraflores Lake has a level of salinity which is already considered "brackish" water (i.e., brackish water is water that has more salinity than fresh water, but not as much as seawater) $[8,9,11,12]$.

Derivations of the different formulas from the different steps in the locks were considered (Figure 2). LS ("left side") in Figure 2, can represent either the Pacific ocean, the Caribbean Sea, or the volume of water contained in a lock at a lower level. Similarly, RS ("right side") represents the volume of water contained in a lock at a higher level such as the lakes Miraflores or Gatun. The initial conditions $(t=0)$ for the 


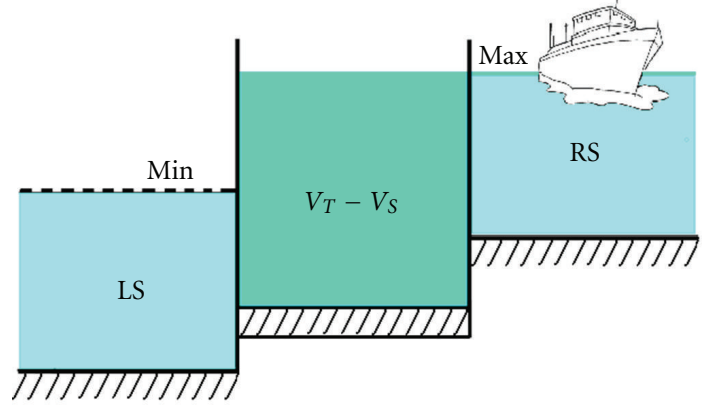

Figure 2: Operation of the locks.

Table 1: Physical dimensions of the Panama Canal Panamax Locks. Panamax is a popular term for the size limit for ships traveling through the Panama Canal. The allowable size is limited by the width and length of the available lock chambers, by the depth of the water in the canal, and by the height of the bridges over the canal [9].

\begin{tabular}{lccc}
\hline Lock & $\begin{array}{c}\text { Width }(\mathrm{m}) \times \\
\text { length }(\mathrm{m})\end{array}$ & $\begin{array}{c}\text { Height over } \\
\text { lock }(\mathrm{m})\end{array}$ & $\begin{array}{c}\text { Depth under or } \\
\text { over PLD }(\mathrm{m})\end{array}$ \\
\hline L1 & $33.53 \times 320.34$ & 7.92 & -15.85 \\
L2 & $33.53 \times 326.44$ & 8.53 & -6.20 \\
L3 & $33.53 \times 326.44$ & 9.45 & +3.44 \\
L4 & $33.53 \times 326.44$ & 8.53 & +3.96 \\
L5 & $33.53 \times 320.34$ & 8.83 & -4.67 \\
L6 & $33.53 \times 320.34$ & 8.53 & -13.50 \\
\hline
\end{tabular}

volume of the lock $(V(0))$ and the salinity $(S(0))$ are given by:

$$
\begin{gathered}
S(0)=S_{0}, \\
V(0)=V_{T}-V_{L},
\end{gathered}
$$

where $V_{T}$ is the volume capacity of the lock, $V_{L}$ is the volume necessary to reach the next level (RS), and $S_{0}$ is the initial salinity of the water inside the lock before the water inside and outside are combined. There are four separate steps in an uplockage or in a downlockage process: (1) the gates on the LS lock open, and the water inside the lock combines with the water pushing the ship into the lock; (2) the gates on the LS lock close and the ship is raised to the next water level; the water of both the LS ( $\left.V_{\mathrm{LS}}\right)$ and RS ( $\left.V_{\mathrm{RS}}\right)$ locks combine and the salinity changes to the new water mix; (3) the gates in the RS lock open, and the water inside the lock combines with the water in the next level (either a lock or a lake); (4) the ship leaves the lock and the water in the lock drains into the lower level (either a lock or the sea); the volume inside the lock is again given by (1). by:

After the four steps above, the salinity of the water is given

$$
S(3)=\frac{S(2)\left[V(2)-V_{\mathrm{RS}}\right]+S_{\mathrm{RS}}\left(V_{\mathrm{RS}}+V_{S}\right)}{V(3)},
$$

where $S(3)$ is the salinity in steps 3 and 4 , since they have the same value. $V_{S}$ is the displacement volume of a ship (average) and $V(3)$ is the volume in step 3. $S(2)$ y $V(2)$ are the salinity and volume of step 2, respectively. Equation (2) needs to be applied for each chamber using the known historic salinities as well as the estimated salinity value of the lower level water given by (3):

$$
S_{N}=S(0)+N[S(4)-S(0)]
$$

$S_{N}$ provides the salinity value by lock (e.g., Miraflores, Pedro Miguel, or Gatun locks) for any quantity $N$ (number of lockages-supposedly only one ship passes through each lockage, so the number of lockages should be the same as the number of ships).

The six locks have different volumes and geometric characteristics so that ships of different drafts can cross the Panama Canal from the Pacific ocean to Gatun Lake. The levels shown in Figure 3 are used with the dimensions shown in Table 1 to calculate the volumes and salinity of the locks when ships cross. In Figure 3 all levels, heights, and depths are referenced to the "Precise Panama Canal Level Reference" (PLD) that matches sea level.

Using the equations of exchange of salinity in the locks, you can set a numerical and differential equations model to define the salinity in Gatun Lake $\left(S_{\mathrm{GL}}\right)$, taking into account the exchange of water (and salinity) in the upper locks of Pedro Miguel and Gatun, and the water contribution by lakes Gatun $\left(V_{\mathrm{GL}}\right)$ and the volumetric inflows of Madden $\left(V_{\text {Madden }}\right)$ with its respective salinity level ( $\left.S_{\text {Madden }}\right)$ and the river tributaries $\left(V_{\text {trib }}\right)$ that flow into these lakes. This relationship is expressed by the following equation:

$$
\begin{gathered}
\frac{d\left(S_{\mathrm{GL}}\right)}{d t}=\frac{V_{\mathrm{GL}} \cdot S_{\mathrm{GL}}+\left(V_{\mathrm{Madden}}+V_{\mathrm{trib}}\right) \cdot S_{\mathrm{Madden}}+\left(V_{L 3}-V_{s}\right) \cdot S_{L 3} \cdot E X_{L 3}+\left(V_{L 4}-V_{s}\right) \cdot S_{L 4} \cdot E X_{L 4}}{V_{\mathrm{GL}}+V_{\text {Madden }}+V_{\text {trib }}+\left(V_{L 3}-V_{s}\right) \cdot E X_{L 3} \cdot N+\left(V_{L 4}-V_{s}\right) \cdot E X_{L 4} \cdot N} \\
\frac{d\left(V_{\mathrm{GL}}\right)}{d t}=\left(V_{\text {Madden }}+V_{\text {trib }}\right)+\left(V_{L 3}-V_{s}\right) \cdot E X_{L 3}+\left(V_{L 4}-V_{s}\right) \cdot E X_{L 4}-\text { Evaporation }(t)+\text { Precipitation }(t),
\end{gathered}
$$

$V_{L 3}$ and $V_{L 4}$ are the volumes of Locks L3 and L4, respectively (See Figure 3). $S_{L 3}$ and $S_{L 4}$ are the respective salinities of L3 and L4 taking into consideration the measured salinity gradients. $E X_{\mathrm{L} 3}$ and $E X_{\mathrm{L} 4}$ are the exchange ratios for Locks $\mathrm{L} 3$ and L4, respectively. Piecewise linear profiles of Evaporation
(Evaporation $(t)$ ) and precipitation (Precipitation $(t)$ ) are added to the calculations of $V_{\mathrm{GL}}$ [13-17].

The different equations were implemented in AnyLogic [7, 18-20]. AnyLogic provides a set of numerical methods for solving differential equations, algebraic-differential 


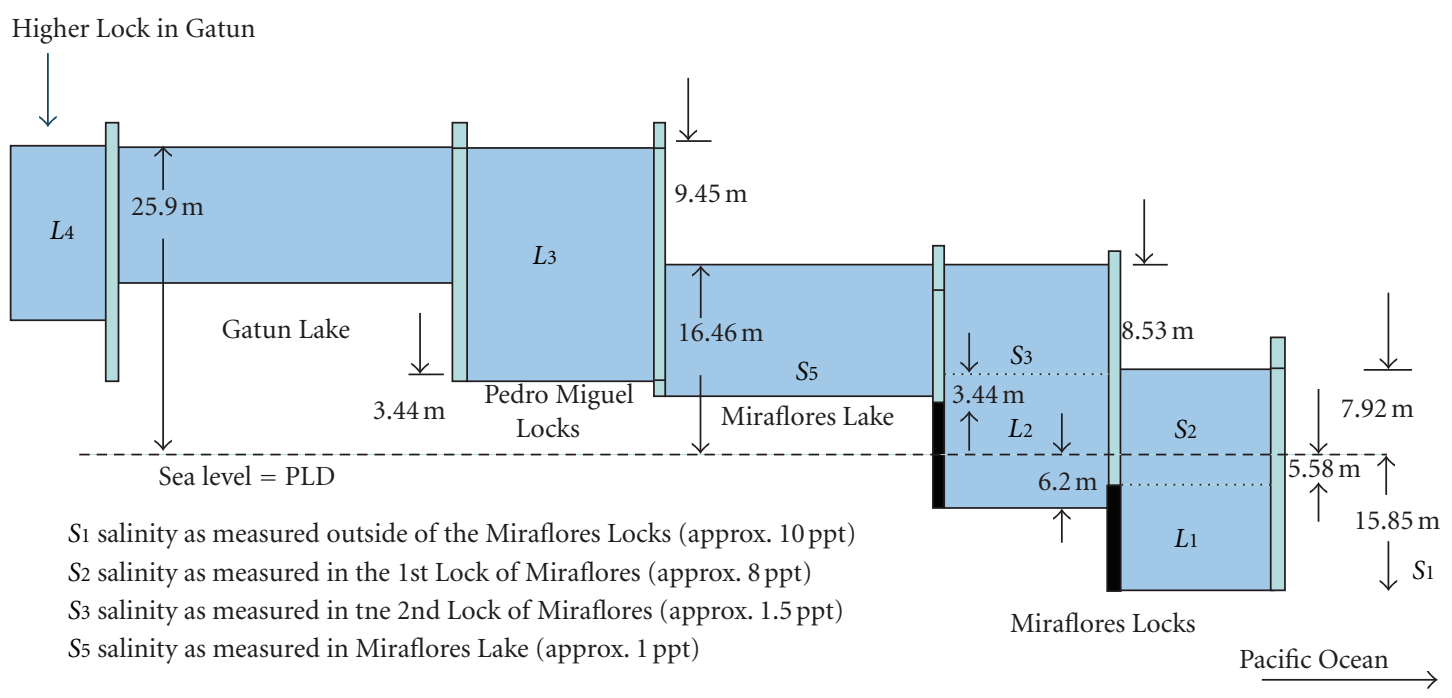

Figure 3: Pacific side of the Panama Canal.

equations, or algebraic equations. AnyLogic chooses the numerical solver automatically at runtime in accordance to the behavior of the system. When solving ordinary differential equations, it starts integration with, fourth-order Runge-Kutta method with fixed steps. Otherwise, AnyLogic plugs in another solver-Newton method. This method changes the integration step to achieve the given accuracy. However, one of the advantages of AnyLogic is its unique hybrid simulation modeling capabilities. We are able to combine the differential equations with a discrete-event system without having to write an interface. This is very important because the diffusion of salinity is a continuous process; however, the lockages produced by the transits of the ships through the canal are essentially a discrete-event process.

\section{Discrete-Event Model Operations}

In discrete-event simulation, the operation of a system is represented as a chronological sequence of events. Each event occurs at an instant time and marks a change of state in the system. For example, if the Panama Canal is simulated, an event could be a ship entering L1, with the resulting system state. The different steps of the transit can be modeled and the "transit rules" for the respective decisions and the utilization of resources (e.g., locks, lakes) and eventually reaching L6 and leaving the canal. The modeling of the different queues is very important to the implementation of the sequential logic. In addition, data collection and information gathering is essential in order to generate random variables (e.g., Gatun Lake transit time) depending on the Panama Canal current operations.

We conducted interviews to learn about the operations and to obtain the different distributions and times. Figure 4 describes some of the generic operations data obtained from the surveys and interviews with personnel from the Panama Canal.
A discrete-event model was developed in AnyLogic, with the respective animations, Queues, Switches, Java Classes, and the Enterprise (i.e., discrete-event) Library (Figure 5). The Switches were complemented with Java statements to capture the logic of assignment of locks and the schedule of the Panama Canal. A ship from the Atlantic Ocean enters the Panama Canal waters at the port of Cristobal. If the ship is not scheduled to transit that day, it will drop anchor and wait for its scheduled transit time. Otherwise, the vessel will sail toward Gatun Locks with a Panama chief pilot in control of the vessel during its transit. The chief pilot will instruct the ship's captain as to the speed and direction of the vessel. The chief pilot also will coordinate with the tug operators, line-handlers, and locomotive engineers as to what assistance they need to provide. The chief pilot remains in contact with the Panama Canal Traffic Control Center (TCC) and each lock tower at all times. The captain relays the chief pilot's instructions to his/her crew members, who perform the proper maneuver [4].

Figure 5 shows the discrete steps of the modeling of a ship going from the Atlantic (ATLANTIC $₫$ - source using probabilistic functions to generate the ships) to the Pacific (PACIFIC $\otimes$ - sink that represent the end of the entity generated by the ATLANTIC process to represent a ship). These discrete process and events are explained as follows.

(1) Entity ship with a specific identification (e.g., 101) and its particular features (e.g., $V_{S}$ ) is generated in ATLANTIC (৫).

(2) The Ship 101 has to wait in a queue (QueueAtlantic 口正䗆) for permission to proceed with the transit in the canal (AtlanticEntrance -o- - a switch is implemented in Java that communicates and coordinates with other switches to model the decisionmaking logic of the Panama Canal). Then, when the permission is received, the ship will navigate the strait (StraitAG $\square$-(D)- 


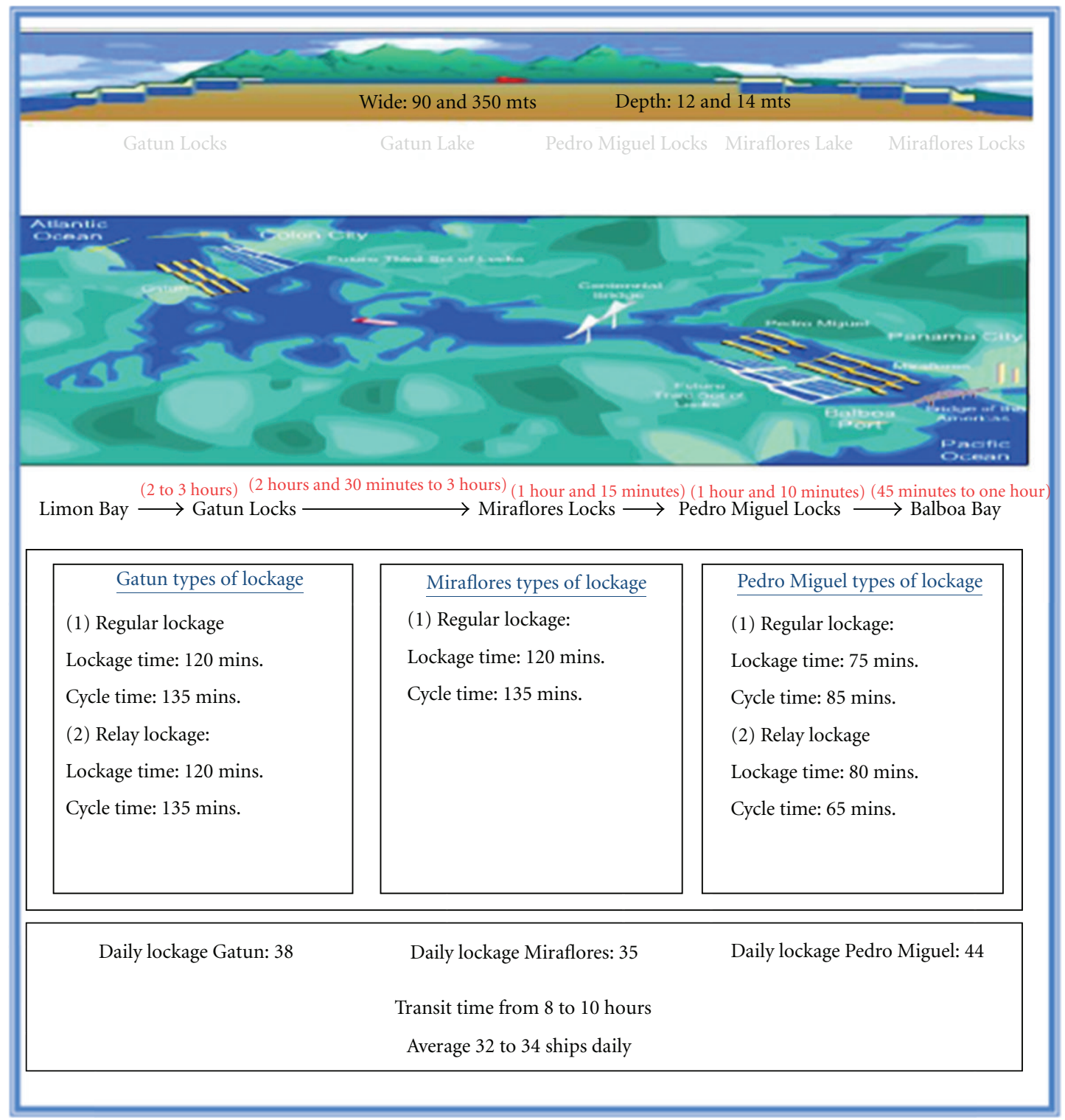

FIgURE 4: General information about the Panama Canal operations.

to the Gatun Locks) until it arrives to the Gatun Locks where it will have to wait for its respective instructions (GCAQueue 响疎). Once instructions are received, the ship proceeds using the lane assigned (by the traffic rules programmed in the GCASwitch 1

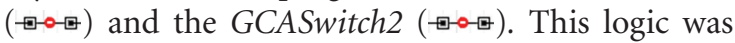
complemented with respective Java code as shown in Figure 5 for GCASwitch1).

(3) The Canal has two lanes each with its own set of locks and Ship 101 is allowed to enter only one lane in Gatun Locks. (A "Select Output" $(<)$ routes the incoming ship to one of the two lanes depending on the logic and external conditions of the switches. The process of each lock has its own respective operational times and their statistical variations have been modeled using the information gathered from the interviews. The ship enters the first lock of Gatun Locks (LockGCA11 巴-(1)-匹 or LockGCA21 -(1)-匹) depending on the initial decision at the GCAQueue provided by the logic of the switches (GCASwitch1 and GCASwitch2). Next, the ship enters the second lock (LockGCA12 - (1)- assuming LockGCA11 was selected initially) or LockGCA22 $\square-(1)-$ (if LockGCA21 was selected). Then, the ship enters the third and final Gatun Lock (LockGCA13 $\square-(1)-\square$ or LockGCA23 (1)- depending on the initial lane decision at GCAQueue).

(4) Finally, at the end of the Gatun Locks a "Combine" $($ ) which is a synchronization point that lets one ship proceed only after another ship arrives (one can be coming from one lane and another from the other lane). The ship has to wait for the signal to continue 


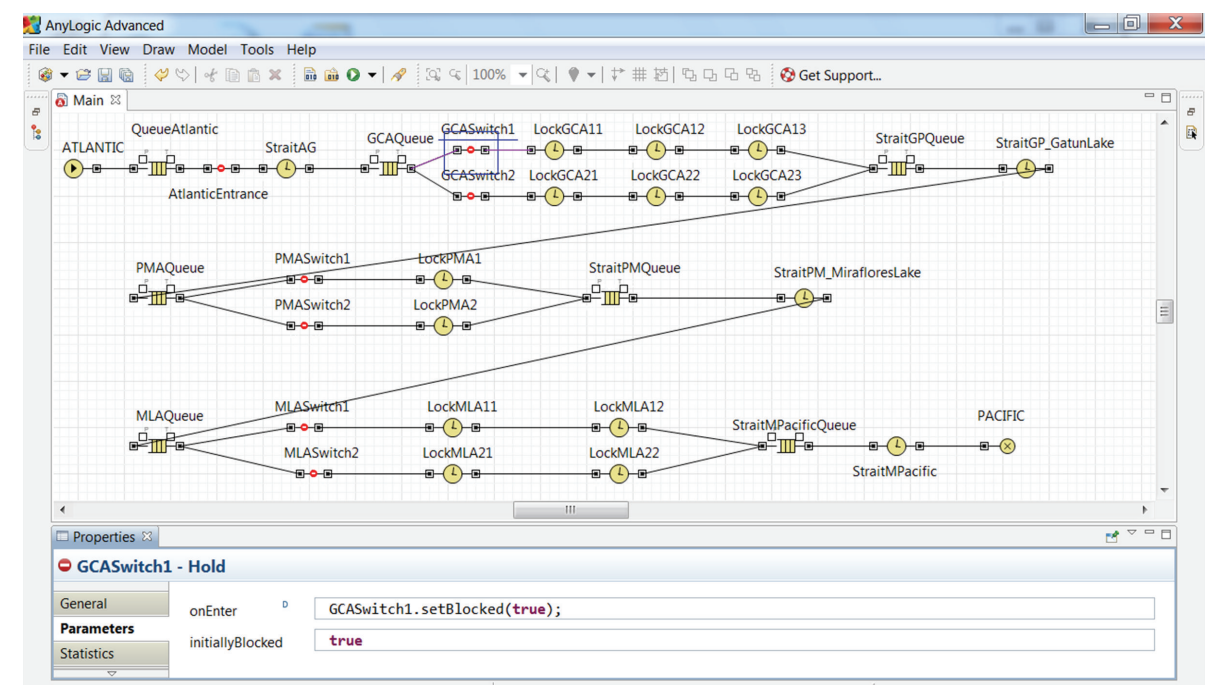

Figure 5: Transit Atlantic-Pacific and some of the implemented sequence/gate logic using Java for GCASwitch 1.

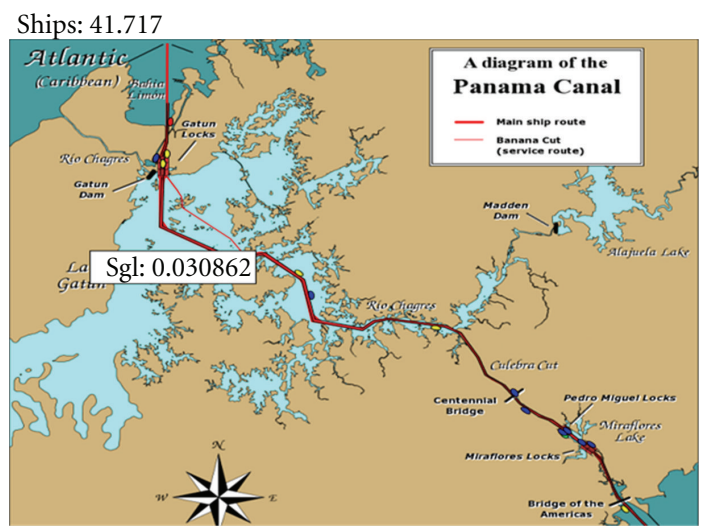

FIGURE 6: Snapshot of the animation that shows the transits and the salinity levels at Gatun lake (Map used in the animation as background was adapted and modified from http://en.wikipedia.org/ wiki/File:Panama_Canal_Rough_Diagram.png, last accessed on January 20,2012 ).

at the respective queue (StraitGPQueue the signal is received, Ship 101 continues navigating Gatun Lake (StraitGP_GatunLake - -(1)- - ) using statistical distributions to model the navigation time and preparing to transit Pedro Miguel Locks.

(5) The ship arrives at the Pedro Miguel Locks where it will have to wait for the respective instructions

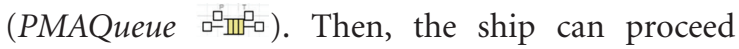
using the set of locks assigned (by the traffic rules programmed in the PMASwitch 1 ( $-\square-\mathbb{*}$ ) and the PMASwitch2 (匹- ) (this logic was complemented with the respective Java code. The ship enters lane one or lane 2 in Pedro Miguel Locks. The ship enters Pedro Miguel Locks (LockPMA1 $\rightarrow$-(1)- or LockPMA2 $\boxplus-(1)-[$ - depending on the initial decision at the

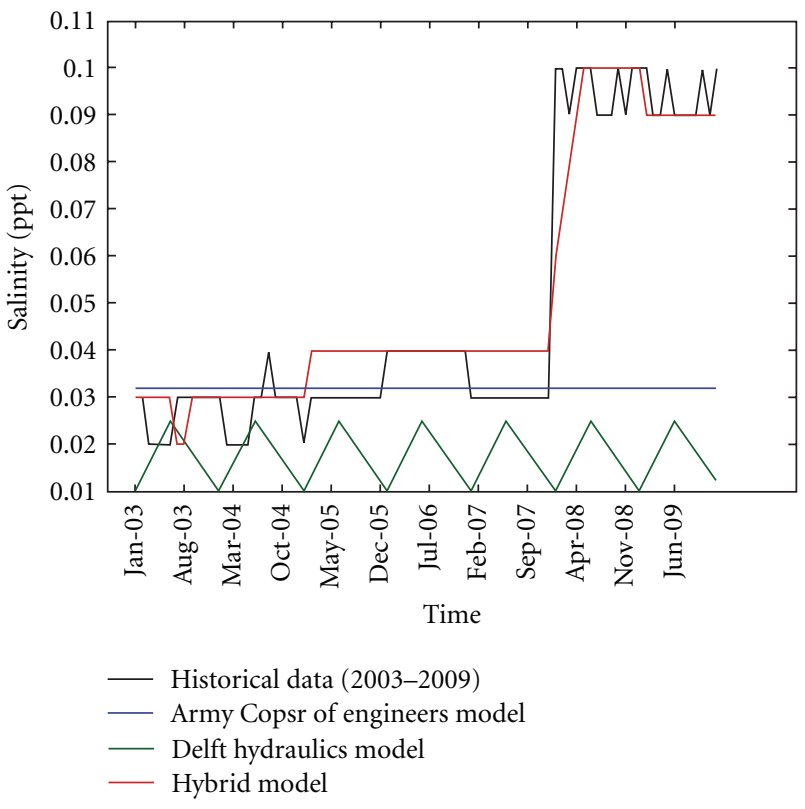

FIGURE 7: Comparisons of the different models against historical data (years: 2003-2009) for the salinity of Gatun Lake.

PMAQueue provided by the logic of the switches GCASwitch1 and GCASwitch2).

(6) Finally, at the end of Pedro Miguel Locks, Ship 101 has to again wait for the signal to continue at the

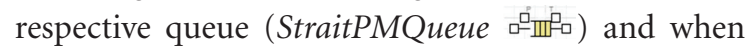
the signal is received, it continues navigating Miraflo-

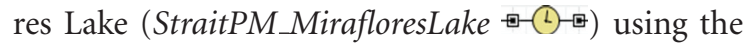
corresponding statistical distributions to model the navigation time in Miraflores Lake.

(7) The ship arrives at the Miraflores Locks where it will have to wait for the respective instructions

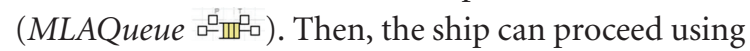




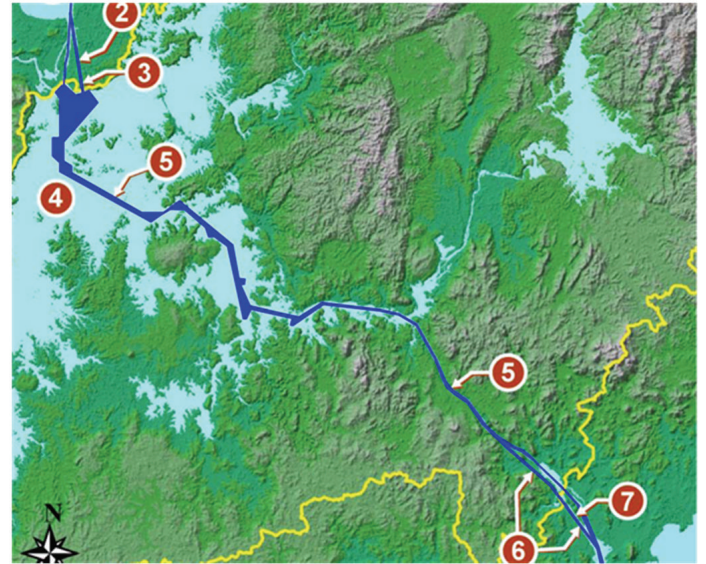

Figure 8: Points 2 (Atlantic side) and 6 (Pacific side) indicate the location of the new set of locks for Post-Panamax ships (adapted and modified from: http://www.pancanal.com/eng/plan/documentos/propuesta/acp-expansion-proposal.pdf, Page 3 of 70, last accessed on January 20, 2012).

the lane assigned (by the traffic rules programmed in

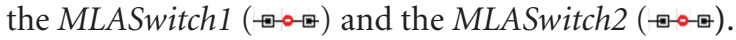

(8) Ship 101 enters the respective lane in Miraflores Locks., The ship enters the first Miraflores Lock (LockMLA11 $\rightarrow-(1)-\square$ or LockMLA21 depending in the initial decision at the MLAQueue provided by the logic of the switches MLASwitch1 and MLASwitch2). Next, the ship enters the second lock (LockMLA12 -(1)- (if LockMLA11 was selected initially, or LockMLA22 -(1)- if LockGCA21 was selected). This second lock is the final Miraflores Lock.

(9) Finally, at the end of the Miraflores Locks Ship 101 has to wait for the signal to continue at the

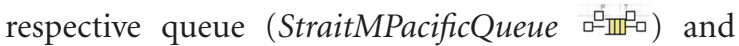
when the signal is received, it continues navigating the strait between Miraflores Locks and Panama

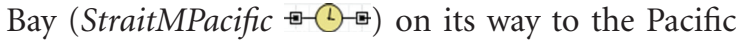
Ocean.

(10) Entity Ship 101 exits at PACIFIC $(\otimes)$ and statistics are generated.

A similar process is required for ships transiting from the Pacific to the Atlantic (where PACIFIC generates ships and ATLANTIC exits the entities). The set of switches and queues simulate the operational logic to allow for the synchronization and coordination needed for these northbound (Pacific/Atlantic) and southbound (Atlantic/Pacific) operations.

\section{Hybrid Model}

AnyLogic has the capability for hybrid modeling. We combined the system dynamics model with the discrete-event model into one model using the capabilities of the Active Object Class from AnyLogic [7, 19]. The discrete-event model feeds the number of lockages at specific discrete even times and a set of differential and algebraic equations is running in continuous time modeling the salinity diffusion produced by the lockages. The Active Object Class from AnyLogic may have multiple concurrent activities that share object local data and object interface. Activities can be created and destroyed at any moment of the model execution. An activity can be described by a Java function or by a Hybrid statechart. Hybrid statecharts can associate a set of differential and algebraic equations with a simple and/or composite state of a statechart, and the user can also specify a condition over continuously changing variables as a trigger of a transition. The currently active set of equations and triggers is defined by the current simple state and all its containers. Therefore, we can have a discrete-event process and the continuous process running concurrently, sharing information, and influencing their behavior.

\section{Animation}

The animation of the model was created using Java. The user can watch the ships pass through the locks as well as visualize the salinity changes in the Gatun Lake. The animation is scalable and hierarchical and it gives us an overview of the Panama Canal process and some aggregate indicators such as salinity. A snapshot of the animation is depicted in Figure 6.

\section{Validation}

The hybrid model was validated using actual transits and salinity field measurements:

(i) actual transit data (Years: 2000-2009);

(ii) salinity level for the Gatun Lake from field measurements (Years: 2003-2009).

The discrete-event model was developed from interviews with the Panama Canal chief pilots and data obtained for each event. Our validation was performed with actual Panama Canal transit data. In addition, the simulation model was executed by generating 100 sets of independent replications (using different random numbers). We compared the simulation to the system by constructing a confidence interval (CI) as shown in Table 2.

The Salinity level output of the hybrid model was compared with those from the real system (Gatun Lake). The values from the real system were provided by field measurements conducted by the Panama Canal Authority at several points within Gatun Lake. Figure 7 provides the comparison of the hybrid model again the historical data (2003-2009).

In addition, the salinity output of our model is compared against two other models for salinity. The model developed by the Army Corps of Engineers predicts the salinity in the years 2003-2009 to be stable at a value of $0.032 \mathrm{ppt}$ [9]. The Army Corps of Engineers did not consider precipitation, evaporation, hydropower plants, fresh water facilities, and spillway flows. The other model was commissioned by the Panama Canal Authority to Delft Hydraulics 


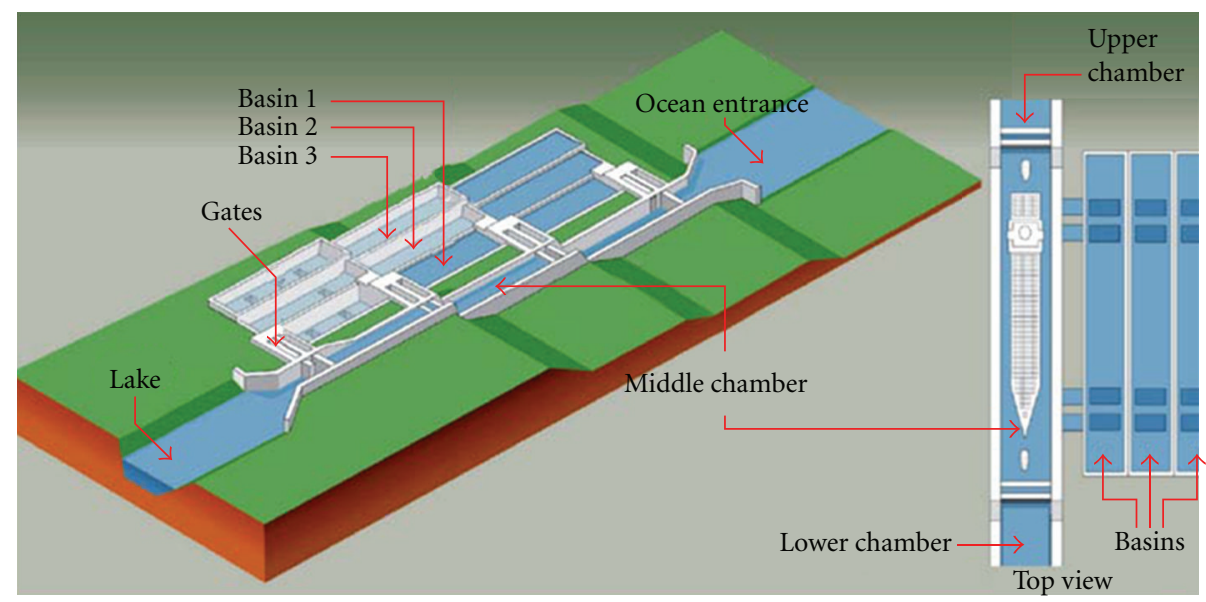

FIGURE 9: Isometric view of the new set of locks using water reutilization basins (Adapted and modified from: http://www.pancanal.com/eng/ plan/documentos/propuesta/acp-expansion-proposal.pdf, Page 4 of 70, last accessed on January 20, 2012).

TABLE 2: Validation metrics.

\begin{tabular}{lcccc}
\hline \multirow{2}{*}{ Measure } & \multicolumn{2}{c}{ Simulation output } & \multicolumn{2}{c}{ Historical data (2000-2009) } \\
& Mean & $95 \%$ C.I. & Mean & 95\% C.I. \\
\hline Transit rate/year & 13416 & $(13173,13659)$ & 13328 & $(12985,13671)$ \\
\hline
\end{tabular}

TABLE 3: Accuracy in salinity simulations.

\begin{tabular}{lccc}
\hline Measure & $\begin{array}{c}\text { Army corps of } \\
\text { engineers model } \\
{[9]}\end{array}$ & $\begin{array}{c}\text { Delft hydraulics } \\
\text { model [12] }\end{array}$ & $\begin{array}{c}\text { Hybrid } \\
\text { model }\end{array}$ \\
\hline $\begin{array}{l}\text { Mean absolute } \\
\text { error (MAE) }\end{array}$ & 0.021 & 0.032 & 0.007 \\
$\begin{array}{l}\text { Mean square error } \\
\text { (MSE) }\end{array}$ & 0.00116 & 0.00189 & 0.00008 \\
$\begin{array}{l}\text { Root mean square } \\
\text { error (RMSE) }\end{array}$ & 0.034 & 0.043 & 0.009 \\
$\begin{array}{l}\text { Percent bias } \\
\left(\text { PBIAS) }{ }^{1}[21]\right.\end{array}$ & $34.66 \%$ & $64.27 \%$ & $-5 \%$ \\
\hline
\end{tabular}

${ }^{1}$ Recommended by the american society of civil engineers (ASCE).

(http://www.wldelft.nl/) [12]. Their model does not consider precipitation and evaporation and uses a constant rate of 36 ships/day. The summary of these comparisons is provided in Table 3.

\section{Conclusions and Further Research}

This research provides a unique example for applying hybrid modeling. Hybrid modeling can benefit organizations with complex operations by providing them with a high prediction capability, which takes into account the internal and external changes taking place in their environment where continuous and discrete variables are present.

The second phase of this project will model the expansion with a third lane and set of locks. Figure 8 indicates the transformation to the current channel. Additions to the current model will have to be performed in order to describe the new traffic patterns involving post-Panamax ships. A lock facility will be located at the Atlantic end of the canal, on the east side of Gatun locks (Figure 8-Point 2). The other facility will be located at the Pacific end of the canal, to the southwest of Miraflores Locks (Figure 8-Point 6) [22].

In addition, the modeling will include new equations to model the salinity diffusion due to the new smart mechanisms being used to build the new locks (water reutilization basins) ensuring the conservation of fresh water. Figure 9 shows the technology to be used for the new set of locks.

\section{Acknowledgment}

This work was sponsored by the Secretaría Nacional de Ciencia, Tecnología e Innovación (SENACYT) of the Republic of Panama under Contract/Project no. FID09-079.

\section{References}

[1] L. A. G. Franzese, L. O. Abdenur, D. Storks, R. C. Botter, and A. R. Cano, "Simulating the panama canal: Present and future," in Proceedings of the Winter Simulation Conference, pp. 18351837, December 2004.

[2] L. Lozano, "Still going strong," The Journal of Commerce, vol. 6, no. 48, p. 24, 2005.

[3] H. R. A. Alvarez, D. Solis, A. R. S. Cano, L. Rabelo, and S. SalaDiakanda, "The system dynamics simulation of the expansion of the Panama Canal," International Journal of Technology, Policy and Management, vol. 9, no. 1, pp. 17-28, 2009.

[4] Global Security, 2009, http://www.globalsecurity.org/military/ facility/panama-canal-transit.htm. 
[5] Panama Canal Authority and Maritime Authority of Panama, "Almost full capacity," in Panama Maritime Handbook 2005/6, pp. 7-13, 2005.

[6] Y. Sandoval, "The dilemma of the expansion costs," Tech. Rep. 409, Martes Financiero -La Prensa, 2005.

[7] A. Borshchev and A. Filippov, "From system dynamics and discrete event to practical agent based modeling: reasons, techniques, tools," in Proceedings of the 22nd International Conference of the System Dynamics Society, Oxford, UK, July 2004.

[8] DHI Water \& Environment, "Review of Saltwater Intrusion and Mitigation Studies and Models for Proposed Post Panamax Locks," 2005, http://www.pancanal.com/esp/plan/ estudios/0276-exec.pdf.

[9] T. Parchure, S. Whilhelms, S. Sarruff, and W. McAnally, "Salinity intrusion in the panama canal," Report from the Coastal and Hydraulics Laboratory, U.S. Army Engineer Research and Development Center, 2000.

[10] Panama Canal Authority, 2005, http://www.pancanal.com/ eng/maritime/notices/n01-05.pdf.

[11] B. Bunch, B. Johnson, and M. Sarruff, "Panama lakes water quality modeling study," Tech. Rep. 03-XX, Report of the Army Corps of Engineering, Engineer Research and Development Center, 2003.

[12] T. Jongeling, "Salt water intrusion analysis-future situation: post-panamax locks," Report of Delft Hydraulics for the Panama Canal Authority, 2003.

[13] B. A. Kokya and T. A. Kokya, "Proposing a formula for evaporation measurement from salt water resources," Hydrological Processes, vol. 22, no. 12, pp. 2005-2012, 2008.

[14] F. I. Morton, "Practical estimates of lake evaporation," Journal of Climate \& Applied Meteorology, vol. 25, no. 3, pp. 371-387, 1986.

[15] F. Morton, "Discussion of "Hydrologic balance model using neutron probe data" by Richard H. Cuenca (November, 1988, Vol. 114, No. 4)," Journal of Irrigation and Drainage Engineering, vol. 117, no. 3, p. 451, 1991.

[16] R. M. Price, W. K. Nuttle, B. J. Cosby, and P. K. Swart, "Variation and uncertainty in evaporation from a subtropical estuary: Florida Bay," Estuaries and Coasts, vol. 30, no. 3, pp. 497-506, 2007.

[17] M. F. Sadek, M. M. Shahin, and C. J. Stigter, "Evaporation from the reservoir of the High Aswan Dam, Egypt: a new comparison of relevant methods with limited data," Theoretical and Applied Climatology, vol. 56, no. 1-2, pp. 57-66, 1997.

[18] M. Garifullin, A. Borshchev, and T. Popkov, "Using anylogic and agent based approach to model consumer market," in Proceedings of the 6th EUROSIM Congress on Modelling and Simulation, 2007.

[19] Y. G. Karpov, R. I. Ivanovski, N. I. Voropai, and D. B. Popov, "Hierarchical modeling of electric power system expansion by anyLogic simulation software," in Proceedings of the IEEE Russia Power Tech (PowerTech '05), June 2005.

[20] C. Wartha, M. Peev, A. Borshchev, and A. Filippov, "Decision support tool-supply chain," in Proceedings of the Winter Simulation Conference, pp. 1297-1301, December 2002.

[21] D. N. Moriasi, J. G. Arnold, M. W. Van Liew, R. L. Bingner, R. D. Harmel, and T. L. Veith, "Model evaluation guidelines for systematic quantification of accuracy in watershed simulations," Transactions of the ASABE, vol. 50, no. 3, pp. 885-900, 2007.

[22] Panama Canal Authority, 2005, http://www.pancanal.com/eng /plan/documentos/propuesta/acp-expansion-proposal.pdf. 

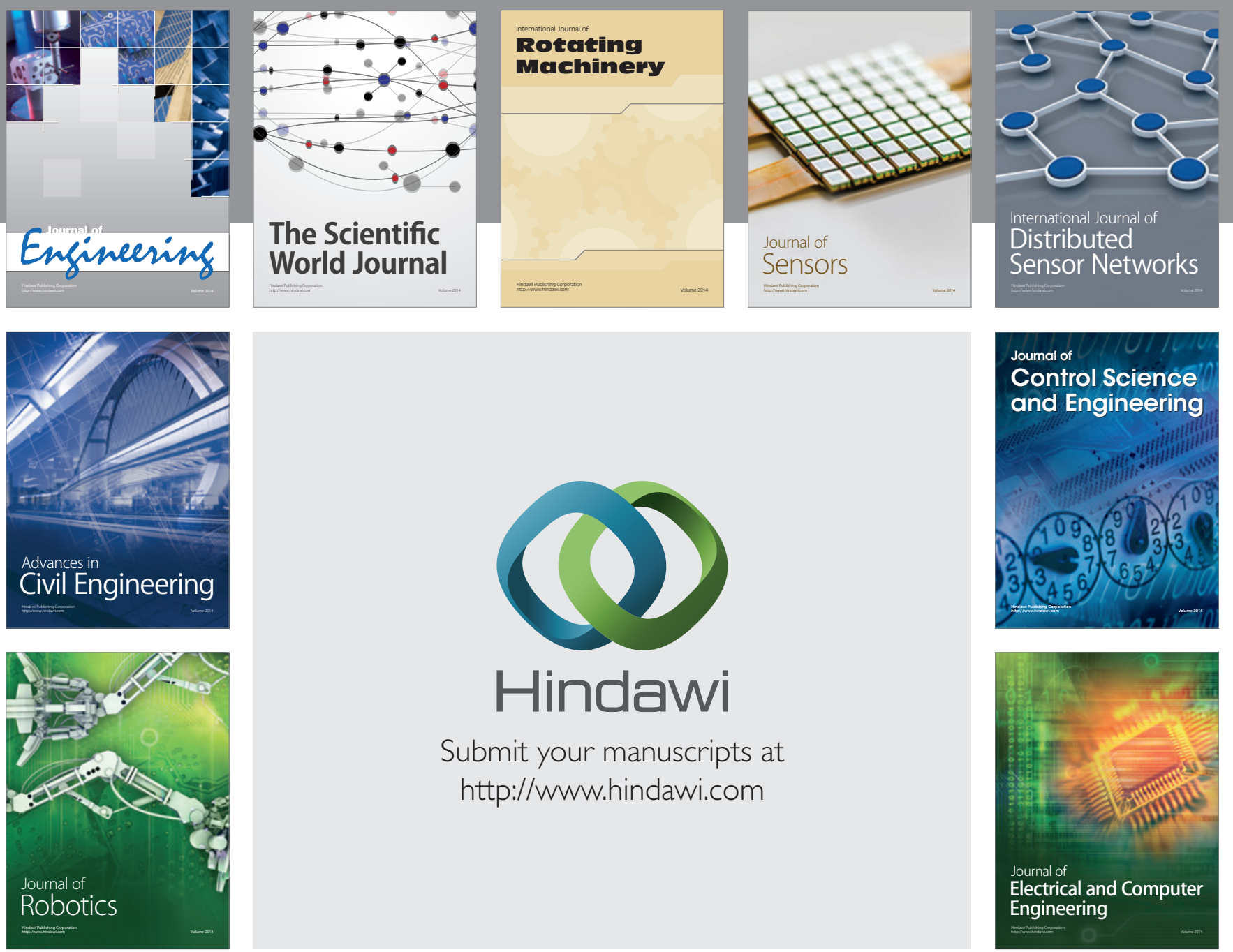

Submit your manuscripts at

http://www.hindawi.com
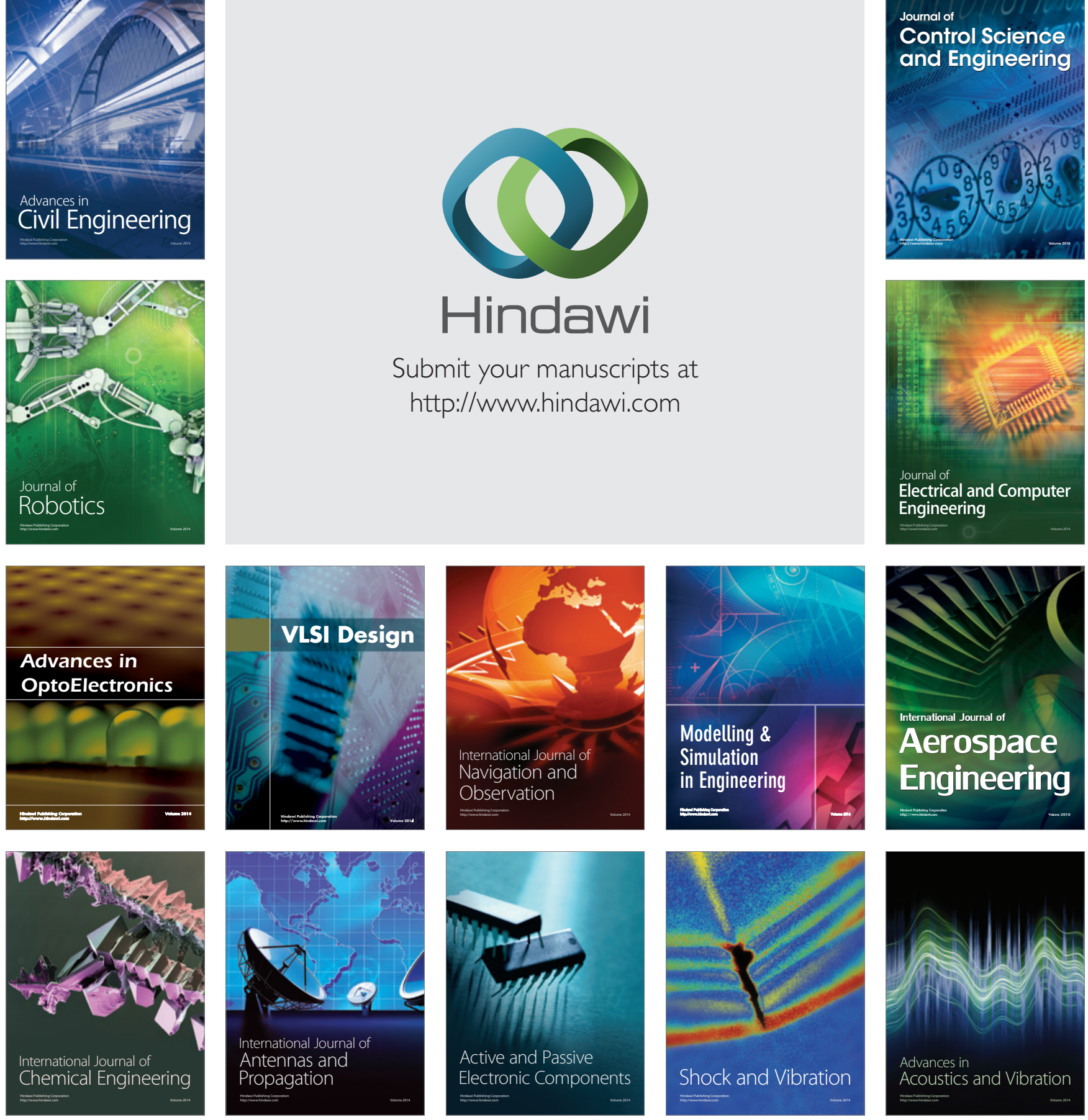